\title{
À SOMBRA DA RUPTURA: NIILISMO ÉTICO E FILOSOFIA NA ERA DAS INCERTEZAS
}

\section{IN THE SHADOW OF THE RUPTURE: ETHICAL NIHILISM AND PHILOSOPHY IN THE AGE OF UNCERTAINTY}

\section{Cláudia Maria Rocha de Oliveira*}

Vivemos em um mundo marcado pela violência, pelo medo e por muitos sinais de morte. Refletir autenticamente sobre este mundo é, inevitavelmente, fazer a experiência do negativo. A possibilidade da impossibilidade de nos realizar humanamente gera angústia e medo. Parece que nossa cultura encontra-se sob a sombra do nada.

Pecorano defende que o cenário da crise da razão, conseqüência dos "horrores de duas guerras mundiais, do fascismo e do nazismo, do holocausto e de Auschwitz", constitui-se como ambiente propício para o infiltrar-se do niilismo na "atmosfera cultural de toda uma época" . Este se torna, pois, uma categoria filosofia fundamental para a reflexão contemporânea.

Ora, transpassados pela angústia gerada pelo niilismo podemos assumir diferentes posições. Para Hegel, por exemplo, pensada dialeticamente, a verdade do espírito apenas pode ser alcançada no dilaceramento absoluto. Portanto, o negativo deve ser encarado diretamente. Isso significa que não devemos propor instrumentos que tornem possível a sua "travessia a qualquer preço"2. Ao contrário, devemos reconhecer que apenas o demora-se nele faz com que o espírito possa alcançar a sua verdade. Demorar-se no negativo, diz Hegel, tem "o poder mágico que converte o negativo em ser"3.

Também Jünger e Heidegger, como mostra Volpi, defendem que se queremos superar o niilismo o melhor é "deixar que o imenso poder do nada seja liberado e que todas as possibilidades do niilismo se esgotem”. Isso não significa, para eles que seja necessário apoiar o niilismo ou se reconhecer nele. Mas, trata-se de "experimentar, em profundidade, o poder

\footnotetext{
* Doutorado em Filosofia pela Pontificia Università Gregoriana (2012). Atualmente é professora assistente e pesquisadora da Faculdade Jesuíta de Filosofia e Teologia.

${ }^{1}$ PeCorano, Rossano. Niilismo. Rio de Janeiro. Zahar, 2007, p.10.

2 VolPI, Franco. O niilismo. São Paulo, Loyola, 1999, p. 93.

${ }^{3}$ Hegel, G. W. F. Fenomenologia do Espírito. São Paulo/ Petrópolis, São Franscisco/Vozes, ${ }^{4} 2007$, § 32.
} 
do nada, convictos de que só com o desdobramento total do niilismo se chegará à sua exaustão e, com ela, à possibilidade de ultrapassá-lo" ${ }^{4}$.

A pergunta que surge é se temos coragem para encarar, como sugere Hegel, a força do negativo. Estaremos dispostos a mergulhar no dilaceramento absoluto e experimentar, em profundidade, o poder do nada? Não seria humanamente mais consolador rapidamente negar o negativo sem nos demorar nele?

Inspirando-me em Hegel, minha proposta aqui não é oferecer soluções consoladoras para o niilismo. Pensar dialeticamente é reconhecer que a verdade do ser é alcançada através da mediação do negativo. O que proponho, então, é contemplá-lo de frente, demorar-me nele. Isso não significa que eu me identifique com o niilismo ou que eu seja niilista. Mas ao reconhecer a força assustadora do negativo presente em nossa cultura, reconheço a necessidade de mergulhar nela e tentar compreendê-la.

Ao tentar compreender o niilismo, no entanto, não pretendo me ater a ele. O filósofo brasileiro Henrique Cláudio de Lima Vaz defende que ao rememorar a história, a reflexão filosófica não deve se tornar prisioneira dos acontecimentos passados, mas deve ser capaz de lançar luzes sobre o presente e, consequentemente, apontar caminhos na direção do futuro. Ao seguir a intuição de Lima Vaz, pretendo então mostrar qual é, de acordo com ele, um possível caminho alternativo que se coloca diante da experiência do niilismo vivida pela cultura contemporânea.

Com o objetivo de decifrar, se é que isso seja possível, em que consiste a força do negativo e, em seguida, encontrar uma alternativa capaz de converter o negativo em positivo, proponho dividir a presente exposição em quatro partes. Em primeiro lugar, esclarecerei o que entendo por niilismo. Em seguida, investigarei quais são as suas raízes. Num terceiro momento, apresentarei conseqüências do niilismo para a cultura contemporânea. Finalmente, perguntarei se é possível indicar alguma alternativa ou via de saída para o niilismo.

\section{0 que se entende por niilismo}

Ao pretender encontrar uma definição para o niilismo, Volpi esclarece que "etimologicamente, o niilismo - do latim nihil (nada) - é o pensamento obcecado pelo nada"5.

\footnotetext{
${ }^{4}$ VOLPI, Franco. O niilismo. São Paulo, Loyola, 1999, p. 95.

${ }^{5}$ VolPI, Franco. O niilismo. São Paulo, Loyola, 1999, p. 09.
} 
Ora, o que constitui tal pensamento? De que modo ele se tornou um fenômeno cultural que nos confronta quotidianamente? Como conviver com a força do negativo?

Causa "essencial da incerteza e precariedade da situação do homem contemporâneo"6, o niilismo gera angústia. A ruptura com os valores tradicionais coloca o ser humano numa situação de desorientação. Não há mais fins últimos capazes de justificar nosso agir e orientar o nosso caminhar. Sendo assim, "o niilismo constitui uma situação de desnorteamento provocado pela falta de referenciais tradicionais, ou seja, dos valores e ideais que representavam uma resposta aos porquês e, como tais, iluminavam a caminhada humana"7 Ele constitui-se como "a 'falta de sentido' que desponta quando desaparece o poder vinculante das respostas tradicionais ao porquê da vida e do ser" ${ }^{\prime 8}$.

Diante da angústia provocada por esta falta de orientação somos tentados a indicar antídotos contra o nada. Queremos ultrapassá-lo do modo mais rápido e menos doloroso possível. Contudo, para Volpi, o niilismo não tem "solução, mas história"9 . Seguindo esta intuição de Volpi, não queremos nesta exposição afirmar imediatamente a primazia do ser sobre o nada. Desejamos sim compreender a força do negativo.

Ao pretender também compreendê-la, Vittorio Possenti, no livro Nichilismo $e$ Metafísica: terza navegazione, defende que encontrar uma definição definitiva do que seja o niilismo não é tarefa fácil. O niilismo não é um fenômeno que pode ser apreendido pela inteligência humana com conceitos claros e distintos. Uma definição para ele deve ser buscada continuamente ${ }^{10}$. Contudo, por outro lado, se olharmos com atenção para a cultura, encontraremos várias características capazes de possibilitar uma compreensão do que seja este fenômeno. Ora, quais características são essas?

Possenti elenca pelo menos quatro características de nossa época que são, para ele, indicadores de que o niilismo se constitui como um "complexo filosófico-cultural"11. São elas: a) "a dissolução de todo fundamento"; b) "a negação de toda finalidade do homem e do cosmos"; c) "a redução do sujeito a mera função", d) "a igual validade de todos os juízos de valor" 12 .

\footnotetext{
${ }^{6}$ Ibid., p. 07.

${ }^{7}$ Ibid., p. 08.

${ }^{8}$ Ibid., p. 55.

${ }^{9}$ Ibid., p.10.

${ }^{10}$ cf.: POSSENTI, V. Nichilismo e Metafísica. Roma, Armando, 2004, p. 29.

${ }^{11}$ Ibid., p. 30.

${ }^{12}$ Ibid., p. 30.
} 
Em primeiro lugar, o niilismo pode claramente ser indicado a partir do anúncio nietzschiano da morte de Deus. A negação da existência de um fundamento transcendente capaz de conferir sentido último às ações do homem e ao mundo constitui-se como consequiência histórica da inversão do vetor metafísico da transcendência para a imanência do sujeito $^{13}$. Contudo, como defende Lima Vaz, o sujeito não suporta o peso ontológico de constituir-se como fundamento último de todo sentido ${ }^{14}$. Em conseqüência a metafísica da subjetividade termina por conduzir, historicamente, ao niilismo.

A primazia conferida ao pólo lógico da razão tornou possível o desenvolvimento da ciência moderna. Ao se apoiar num modelo unívoco de racionalidade, as ciências empíricoformais, por um lado, se mostraram importantes para a vida do homem. $\mathrm{O}$ avanço das ciências tornou possível, por exemplo, a criação de equipamentos e tecnologias sofisticados que garantem a produção de alimentos em escala muito maior do que as antigas técnicas de agricultura e pecuária. Além disso, muito se descobriu a respeito de doenças. A medicina hoje tem o poder de prolongar os nossos dias sobre a terra.

Contudo, por outro lado, a crescente autonomia alcançada pelas ciências coloca para o homem questões existenciais complexas que não encontram solução no nível da própria razão científica. Ao negar a primazia do pólo metafísico da razão, o homem moderno se viu obrigado a conviver com a falta de razão de ser de seu próprio ser. Neste sentido, Gilbert afirma que

O homem contemporâneo, fascinado pela ciência, é esmagado por ela. A ciência, por mais eficiente que seja, uniformiza o nosso universo e produz uma cultura mundial em que muitos não se reconhecem. Os sucessos técnicos entusiasmam ao mesmo tempo em que atordoam e inquietam. Precisamos ficar livres de nossa fascinação pela ciência. Esta ignora o princípio ontológico, o ser que une diversificando. Ela reduz a diversidade dos entes materiais à unidade dos princípios formais ${ }^{15}$.

Sem referência a um fundamento capaz de orientar o destino do homem, a visão teleológica própria da visão de mundo clássica cede lugar ao pragmatismo generalizado orientado por um modelo operacional de racionalidade. Este promove uma mudança na compreensão da temporalidade. Se antes o passado e a tradição eram valorizados como

\footnotetext{
${ }^{13}$ Sobre a questão da inversão da primazia do pólo metafísico para o pólo lógico da razão ver OLIVEIRA, C.M.R. Metafísica e Ética: a filosofia da pessoa em Lima Vaz como resposta ao niilismo contemporâneo. São Paulo, Loyola, 2013, Cap. 1, pp. 31-64.

14 cf.: Lima VAZ, H.C. Raízes da Modernidade. São Paulo, Loyola, 2002, p. 127.

${ }^{15}$ Gilbert, Paul. A Paciência de Ser. São Paulo, Loyola, 2005, p. 15.
} 
tesouro que deveria ser acolhido, agora eles são desprezados e abandonados como supérfluos e ultrapassados. O futuro, antes visto como o abrir-se de possibilidades que apontavam na direção da realização do homem e do mundo, adquire uma face obscura e enigmática que é deixada de lado como indecifrável e sem consistência. Somos, então, condenados a viver o presente. O presente mostra-se agora opaco, sem referência ou relação seja com o passado seja com o futuro. Nesse sentido, o homem moderno está condenado, como afirma Lima Vaz, a suportar o tédio do presente. Nele ele deve confrontar-se continuamente com a angústia gerada pelo vazio, pelo nada.

Volpi esclarece que "quando a transcendência perde sua força vinculadora e emudece, o homem abandonado a si mesmo reclama sua liberdade" ${ }^{16}$. Porém, o avanço da primazia da racionalidade técnico-científica conduz ao efetivo domínio da razão poiética sob os demais usos da racionalidade. Assistimos, então, ao abandono da clássica divisão aristotélica da razão. A razão prática, entendida como razão eminentemente teleológica, que tem como fim a realização do sujeito na sua mais radical humanidade, deixa de ser a razão que orienta às ações do homem contemporâneo. Estas passam a se orientar a partir de um modelo de racionalidade operacional. Em consequiência, os princípios axiológicos deixam de ser entendidos como critérios objetivos supra-pessoais. Passam a ser vistos como princípios estabelecidos a partir dos próprios atos humanos com o objetivo de satisfazer necessidades imediatas. A liberdade é, então, pensada apenas como liberdade de arbítrio.

Mas, se os princípios axiológicos não são mais princípios que possuem um caráter objetivo e suprapessoal, qualquer indivíduo pode defender qualquer valor. Acentua-se uma cisão entre o âmbito privado e o âmbito público da vida humana. Neste, o indivíduo deve assumir um papel social e responder às necessidades impostas por um modelo de racionalidade operacional. Ele é reconhecimento não por aquilo que ele é, mas pela função que realiza, ou seja, pelo papel social que assume. No âmbito privado, por sua vez, o indivíduo passa a orienta-se por valores que não podem ser justificados ou fundamentados intersubjetivamente. Os valores, nesse caso, perdem toda a consistência. Transformam-se em mero objeto de preferências subjetivas. Em conseqüência, como afirma Volpi, a ética e a moral passam a ser contempladas em sua beleza como "fósseis raros"17.

Diante desta situação, Lima Vaz defende que falta a nossa civilização "uma alma ética". Isso significa que, embora o desenvolvimento da técnica coloque ao nosso dispor uma

\footnotetext{
${ }^{16}$ VOLPI, Franco. O niilismo. São Paulo, Loyola, 1999, p. 17.

${ }^{17}$ Ibid., p. 140.
} 
infinidade de possibilidades de agir, não somos mais capazes de indicar as "razões de ser livre". Paradoxalmente, assistimos a uma perda do humano nas próprias obras do homem. Justamente nisto encontra-se a "essência do niilismo ético"18.

Todas essas características do niilismo nos revelam que ele se constitui como um fenômeno histórico-cultural de graves conseqüências para a vida humana. Ao igualar o ser e o nada na atividade interrogante de nossa inteligência, o niilismo inviabiliza a afirmação de um sentido para a existência do homem e do mundo. Ao não distinguir o bem e o mal no movimento desejante de nossa vontade, o niilismo faz com que os juízos de valor percam sua consistência. Com outras palavras: à medida que afirma a validade de todos os juízos de valor, o niilismo conduz a um relativismo generalizado que, em conseqüência, nega toda finalidade e toda possibilidade de orientação para os atos humanos.

Ora, diante deste fenômeno histórico-cultural caracterizado pela força do negativo, ou seja, diante do niilismo, o caminho que escolhemos aqui é aquele que nos permite, de algum modo, mesmo que com espanto, contemplá-lo. Isto significa, entre outras coisas, colocar-se disponível para investigar qual a gênese desse fenômeno. Este será, então, o caminho que seguiremos no que se segue.

\section{As origens do niilismo}

Como vimos, o niilismo ético caracteriza-se pela desvalorização de todos os valores, ou melhor, como afirma Possenti pela afirmação de que eles "são subjetivos e escolhas vãs em base às próprias preferências"19. Sem possibilidade de serem justificados ou fundamentados intersubjetivamente, os valores perdem sua consistência e se tornam incapazes de orientar os atos humanos na direção da realização da própria humanidade do sujeito.

Embora o niilismo ético seja talvez o fenômeno do negativo mais visível na cultura contemporânea, Possenti defende que ele só é possível por causa de um niilismo teórico prévio $^{20}$. Ao caminhar na mesma direção, Lima Vaz também parte do pressuposto de que o niilismo metafísico encontra-se na base do niilismo ético ${ }^{21}$. Caracterizado ou definido, a partir de Heidegger, como esquecimento do ser, o niilismo metafísico é entendido por Possenti

\footnotetext{
${ }^{18}$ LIMA VAZ, H.C. Escritos de Filosofia III: Filosofia e Cultura. São Paulo, Loyola, 1997, p. 137.

${ }^{19}$ PossenTI, V. Nichilismo e Metafísica. Roma, Armando, 2004, p. 30.

${ }^{20}$ cf.: Ibid., p.30

${ }^{21}$ Apresentei anteriormente a posição de Lima Vaz em Oliveira, C.M.R. Metafísica e Ética. São Paulo, Loyola, 2013.
} 
como "o processo nientificante da verdade do ser" 22 . Este processo, de acordo com ele, está diretamente relacionamento com o desenvolvimento de um paradigma especulativo antirealista que ao invés de afirmar a identidade intencional entre o ser e o pensar, defende que a representação constitui-se como termo último do conhecimento. Sendo assim, "a essência do niilismo especulativo consiste (e tem origem) na incapacidade de atingir em uma visualização eidético judicativa o ser"23.

Para a metafísica clássica o ser se revela no juízo, mas não coincide com o mesmo. A representação formal do ser afirmado no juízo constitui apenas uma mediação por meio da qual é possível estabelecer uma relação mais estreita entre ser e pensar. A inteligência espiritual torna possível, como afirma Possenti, "uma apreensão noética da realidade, na qual o intelecto 'se casa' ou celebra as núpcias com o ser da coisa, alcançando um alto grau de atuação de si mesmo no contato com o núcleo de inteligibilidade e de mistério que existe no ser" 24 . Sendo assim, "no ato de pensar intelectualmente não acontece uma representação [...] mas uma percepção respeitosa" que "acolhe o ser como é, e o deixa ser" 25.

Contudo, na modernidade, a relação intencional imediata entre o pensamento e o ser foi interrompida. O abandono da inteligência espiritual gerou uma separação entre o pensamento e o ser. A representação, que antes era uma mediação que tornava possível acolher o objeto real, passa a ser afirmada como o fim ou o termo do pensamento.

Lima Vaz também defende que o niilismo metafísico constitui-se como face oposta do realismo clássico. A posição central defendida pelo realismo clássico, como mostra Possenti, consiste na afirmação de que "o conhecimento não termina na idéia/conceito, mas na coisa, no sentido de que o objeto imediatamente alcançado pelo ato cognoscitivo [...] é a própria coisa, não um seu substituto",26.

Isso significa, como vimos, que a idéia ou a representação apresenta-se apenas como uma mediação através da qual se torna possível colher ou acolher a manifestação do objeto real. A alteridade da realidade é, então, acolhida pela inteligência que se abre intencionalmente a ela. Sendo assim, se a inteligência não fosse compreendida como abertura intencional a uma alteridade que ao mesmo tempo se identifica, mas também se opõe a ela,

\footnotetext{
22 Possenti, V. Nichilismo e Metafísica. Roma, Armando, 2004, p. 33.

${ }^{23}$ Possenti, V. Nichilismo e Metafísica. Roma, Armando, 2004, p. 34.

${ }^{24}$ Ibid., p. 34.

${ }^{25}$ Ibid., p. 40.

${ }^{26}$ Ibid., p. 37.
} 
ela "giraria sobre si mesma, produziria apenas as próprias representações e não conheceria nada de novo",27.

Ao pressupor a separação entre ser e pensar, a racionalidade técnico-científica apóia-se em uma noção unívoca de razão que se mostra incapaz de pensar o simples existir do sujeito singular. Em conseqüência, o existir singular, que atualiza e concretiza o nosso ser no mundo e no tempo da história, transforma-se num enigma para a razão. Isso acontece, como defende Lima Vaz, porque "a existência, no seu simples ato de existir, é irredutível aos procedimentos operacionais da razão" 28 .

Ao igualar o ser e o nada no movimento interrogante de nossa inteligência, o niilismo metafísico impede que a interrogação a respeito do sentido de ser, ou ainda, a interrogação a respeito do sentido de existir encontre resposta capaz de ultrapassar a dimensão do subjetivismo e da arbitrariedade.

Interrogar a respeito da gênese do niilismo supõe, então, colocar a questão sobre a origem do paradigma especulativo anti-realista, ou ainda, sobre a origem da separação entre o pensamento e o ser.

Lima Vaz identifica a origem histórica ou a raiz última do niilismo nas controvérsias doutrinarias que tiveram lugar a partir do século XIII e se prolongaram nos séculos sucessivos. De modo mais preciso, a gênese do niilismo pode ser identificada na substituição da teoria aristotélico-tomista da identidade intencional entre o ato do conhecimento e o objeto conhecido pela teoria scotístico-nominalista que afirma o objeto representado como termo do ato do conhecimento ${ }^{29}$. O niilismo tem origem última, portanto, no "triunfo da representação sobre o ser" mediação estabelece uma relação de identidade intencional do ato cognoscitivo com o objeto extramental" e passa a ser entendida como o "termo imediato", ou seja, "o id quod da intenção cognoscitiva"31.

Esta progressiva substituição da teoria aristotélico-tomista da identidade intencional entre ser e pensar tem origem, de acordo com a interpretação de Lima Vaz, a partir de Duns Scoto. Ao propor uma reconstrução sistemática e rigorosa da metafísica, ele abandona a noção analógica de ser e afirma o ser de modo unívoco. Surge, então, o modelo onto-teológico que

\footnotetext{
${ }^{27}$ Ibid., p. 39.

${ }^{28}$ Lima VAZ, H.C. Raízes da Modernidade. São Paulo, Loyola, 2002, p. 102.

${ }^{29}$ cf.: LIMA VAZ, H.C. Escritos de Filosofia III: Filosofia e Cultura. São Paulo, Loyola, 1997, pp. 160-161.

${ }^{30}$ Ibid., p. 162.

${ }^{31}$ Ibid., p. 162
} 
pensa o ser como hierarquia de essências e não consegue dar conta da diferença ontológica que existe entre os entes e entre os entes e o ser. Este modelo onto-teológico é alvo da crítica de Heidegger. Ele teria conduzido, historicamente, ao esquecimento do ser e, portanto, ao niilismo metafísico.

Ao pensar o ser de modo unívoco, o modelo onto-teológico, por sua vez, tornou possível o desenvolvido da racionalidade empírico-matemática e, conseqüentemente, viabilizou o desenvolvimento da episteme moderna.

Contudo, como vimos, a ciência moderna não consegue pensar o simples existir do homem no mundo. Ela não é capaz de conferir um sentido autêntico a vida do homem e às suas obras. Logo, no abandono do modelo de racionalidade analógica, que permitia pensar de modo mais adequado a diferença ontológica entre o ser e os entes, podemos apontar a origem do progressivo triunfo da representação sobre o ser. Além disso, nesse abandono também podemos indicar a origem da progressiva inversão do vetor da transcendência para a imanência. O sujeito, dotado de razão, passa a ser afirmado como instância e critério último do exercício da própria liberdade.

A questão a respeito do sentido de ser, portanto, esta intimamente articulada com a questão dos fins. Sendo assim, o niilismo especulativo encontra-se na base do niilismo ético. A separação entre ser e pensar, que está na origem do niilismo especulativo, também pode ser considerada a raiz da negação de toda finalidade do homem e do cosmos, da indistinção entre o bem e o mal no movimento de nossa vontade.

Ora, ao conferir primazia ao modelo de racionalidade empírico-matemática, a modernidade termina por submeter a praxis ao modelo e às exigências da razão poiética. Nesse sentido Lima Vaz comenta que "a primazia do saber codificado no logos científico ou técnico tende a submeter a praxis à necessidade do discurso racional ou às condições reguladoras da norma técnica o que, na mesma medida, limita a possibilidade do seu autodeterminar-se como praxis livre" 32 . Na atualidade, portanto, "o conhecimento normativo da ação não é mais situado na esfera ética, mas transferido para o terreno do saber técnico aplicado à organização da sociedade"33.

Uma das conseqüências dessa submissão da praxis à poiesis consiste no progressivo abandono da noção de energeia. Com outras palavras: "a captação da praxis pela esfera da poiesis e sua submissão às regras da téchne tem, como conseqüência, o desaparecimento do

\footnotetext{
${ }^{32}$ Lima VAZ, H.C. Escritos de Filosofia II: Ética e Cultura. São Paulo, Loyola, 1991, p.82.

${ }^{33}$ Ibid., pp. 83-84.
} 
conceito de energeia, fim imanente e perfeição do ato. Este esgota seu dinamismo no movimento transiente da produção da obra ad extra"34. Ora, para Lima Vaz, justamente no abandono do conceito de energeia encontra-se a origem do niilismo ético.

Como sabemos, Aristóteles estabelece distinção entre teoria, praxis e poiesis. A teoria tem como fim o conhecimento por ele mesmo. Ela pode ser entendida como a atividade humana voltada para a contemplação da Verdade. A atividade poietica, por sua vez, embora tenha origem no sujeito, tem em vista a realização de uma obra que é extrínseca ao próprio sujeito. Nesse caso, o operar humano se desenvolve e se realiza no domínio do objeto. Já a práxis não tem em vista a realização de nada que lhe seja extrínseco. O seu fim é a própria realização do sujeito agente. Nesse caso, a obra a ser realizada não se constitui como objeto. A obra que cada um é chamado a realizar através da praxis é o próprio existir, ou melhor, a própria vida.

Ao estabelecer distinção entre a teoria, a praxis e a poiesis, Aristóteles confere especificidade para a praxis e garante um lugar próprio para a ética no domínio dos saberes. Ao defender que a ação não se identifica com a produção, ele propôs pensar a ação como um ato que contém em si mesmo a sua própria perfeição, ou seja, como energeia. Nesse sentido Lima Vaz esclarece que "enquanto o finalismo da téchne é orientado para a perfeição do objeto fabricado, o finalismo da praxis, regido pela theoria, é orientado para a perfeição do próprio agir, para a sua arete" 35 . Em conseqüência, a "liberdade assume, aqui uma feição eminentemente ativa como prossecução de um alvo ou realização de um fim e, nesse sentido, ela é, como autodeterminação ou senhorio sobre si mesmo (autárqueia), a própria razão de ser dessa perfeição ou ato (enérgeia) que é a praxis"36.

Ora, a origem do niilismo ético é indicada, justamente, no abandono do conceito de energeia, ou seja, no abandono da forma da práxis entendida a partir da plenitude de sua atualidade. Logo, para compreender melhor o que isso significa é necessário entender quais são as conseqüências deste acontecimento.

\section{Conseqüências do abandono do conceito de energeia}

Lima Vaz defende que

\footnotetext{
${ }^{34}$ Ibid., p. 99.

${ }^{35}$ Ibid., p. 89.

${ }^{36}$ Ibid., p. 90.
} 
Despojada da coroa da enérgeia, da sua perfeição imanente, a práxis passa a ser pensada segundo a categoria básica da igualdade aritmética que reflui sobre os agentes, tornando-os iguais e diferenciados apenas pelo simples número com que são contados na sequiência de uma sucessão numérica. A ação se exaure no seu objeto, o homem é, primeiramente, um "ser produtor" (Marx), e o desaparecimento do conceito de enérgeia traz consigo de um lado o esvaziamento do conceito de virtude (areté) como perfeição e medida qualitativa da própria ação e, de outro, a radical impossibilidade de se constituir uma teoria da praxis como teoria do bem propriamente humano - como teoria ética ${ }^{37}$.

Temos pois, indicadas aqui, duas consequiências fundamentais do abandono da noção de energeia. A primeira consiste no esvaziamento da noção de virtude. A segunda, por sua vez, está diretamente relacionada com a impossibilidade da elaboração de uma ciência da práxis, ou melhor, da ética.

Sabemos que para Aristóteles a virtude ética deve ser adquirida através da realização efetiva de constantes atos éticos, ou melhor, através do hábito. Ora, a praxis se constitui enquanto tal à medida que é orientada pela sabedoria prática, ou seja, pela phronesis. Esta se constitui "como estrutura dianoética fundamental do agir ético"38. Enquanto tal, "ela não está presente na práxis em razão de si mesma, mas em razão do próprio exercício do agir"39.

Primeira virtude dianoetica, a phronesis orienta o sujeito para que ele seja capaz de estabelecer o justo meio entre o excesso e o falta, isto é, entre dois vícios. Ao orientar-se pela reta razão, que a phronesis prescreve, o sujeito age de acordo com o bem. Isso significa que ele conduz a sua ação através da razão prática, entendida como entrelaçamento de razão e vontade, em direção da sua auto-realização.

Lima Vaz, ao comentar Aristóteles, explica que nesse sentido "a phronesis como virtude da razão reta (orthòs lógos)" estabelece "a media razoável entre os extremos para as virtudes éticas" e, também, "assinala justamente a presença do logos regulador e ordenador no fluxo contingente das ações singulares" $"$.

Ao esclarecer o que constitui a razão própria da práxis segundo Aristóteles, Lima Vaz esclarece que, quando pensamos a razão prática como entrelaçamento de razão e de vontade isto significa que "Razão e Liberdade são compreendidas, na verdade, sob um termo único (boúleusis), designando um só e único movimento espiritual que orienta e conduz a práxis ao

\footnotetext{
${ }^{37}$ Ibid., p.111.

${ }^{38}$ Ibid., p. 103.

${ }^{39}$ Ibid., p. 103.

${ }^{40}$ Ibid., p. 106.
} 


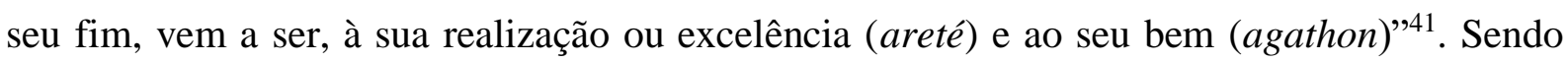
assim, a práxis deve ser compreendida como agir orientado pela razão prática. Esta torna possível a deliberação e a escolha segundo bem.

Contudo, a partir do momento em que o conceito de energeia é deixado de lado e, consequentemente, a praxis perde a sua especificidade, também o conceito de virtude perde a sua razão de ser. As ações não se orientam mais na direção da realização do próprio agente. Elas têm em vista agora a realização de objetos. Os valores passam a ser constituídos unicamente através de pragmatismo generalizado que não tem mais, necessariamente, referência ao horizonte do bem. Instaura-se, assim, o niilismo.

A segunda conseqüência do abandono do conceito de energeia encontra-se na impossibilidade da constituição da Ética compreendida como ciência da práxis. Ora, se a praxis perde a sua especificidade, ela passa a ser tratada como mero meio para alcançar fins extrínsecos a ela mesma. Ela adquire um caráter meramente operacional. A ética, entendida como ciência da práxis perde a sua razão de ser.

Além disso, a crescente primazia da racionalidade matemático-operacional está na base daquilo que o autor alemão Karl-Otto Apel chama de sistema de complementariedade ocidental. De acordo com este sistema apenas pode ser aceito intersubjetivamente os discursos neutros das ciências empírico-formais. Todo discurso referente à dimensão valorativa da vida humana é, por esse sistema de complementariedade, relegado à dimensão do subjetivismo e da arbitrariedade.

Ora, se os valores se tornam subjetivos, isso significa, que cada sujeito, a partir de seu ponto de vista próprio, pode defender qualquer valor. Cada indivíduo passa a ser medida de toda dimensão valorativa da própria vida. Em conseqüência, os valores se tornam relativos. Não é mais possível distinguir o bem e o mal como princípios da atividade desejante de nosso vontade. Não é possível propor uma ciência da práxis. Tem lugar, portanto, o niilismo ético.

\section{Existem alternativas para o niilismo?}

Vimos que o niilismo compreendido como fenômeno histórico-cultural, tem origem a partir de profundas rupturas com a tradição. Estas rupturas, sejam no horizonte da afirmação do ser, sejam na dimensão do agir, fazem de nossa era um tempo de incertezas. Em

${ }^{41}$ Ibid., p. 91.

Sapere Aude - Belo Horizonte, v. 6 - n. 12, p. 816-831, Jul./Dez. 2015 - ISSN: 2177-6342 
consequiência, o homem contemporâneo parece caminhar de modo errante. Os valores, que antes serviam de bussola capaz de indicar o norte na direção do qual a consciência moral individual deveria ser formada, sofrem um gradativo processo de dissolução. A dissolução dos valores, no entanto, gera insegurança. Sem referências, assistimos atônitos ao crescimento assustador da agressividade e da violência.

A pergunta que surge é: até quando resistiremos ao mal-estar gerado pela indistinção entre o ser e o nada e pela indistinção entre o bem e o mal? Ou ainda: até quando seremos capazes de viver sob a sombra do niilismo?

Para Lima Vaz, se a cultura insistir em caminhar na direção da continua afirmação da primazia do saber técnico, sem conferir novamente uma especificidade ao saber prático e sem reconhecer a necessidade de uma abertura do sujeito à contemplação da verdade e do bem que ultrapassam qualquer determinação formal, estaremos condenados ao sem sentido e à falta de orientação.

Ele defende, então, a necessidade de reencontrar um modo de pensar o ser e o agir a partir de um modelo de racionalidade analógica que permita reafirmar o Absoluto transcendente como fundamento último do existir e do agir humanos ${ }^{42}$.

Diante dessa necessidade ele propõe uma reflexão que nasce da interrogação que o próprio sujeito faz a respeito de si mesmo: “Quem sou eu?”. Ao perguntar pelo seu próprio ser, o homem faz a experiência primeira da sua corporeidade. Somos necessariamente seres situados no tempo e na história. Somos corpo.

Contudo, a categoria de corporeidade não é capaz de dizer a totalidade do que sou. A dimensão de exterioridade não é a única dimensão capaz de definir o meu próprio ser. Sou também meu mundo interior. Sou desejo e imaginação. Sou meu psiquismo.

A oposição dialética entre mundo exterior e mundo interior, isto é, entre corpo e psiquismo deve, no entanto, ser suprassumida numa unidade constitutiva. Dimensão estrutural fundamental do ser humano, o espírito confere unidade às dimensões estruturais que definem o ser do homem.

Ao afirmar-se como espírito o homem faz a experiência de seu próprio ser como ser dotado de inteligência e de vontade. Enquanto inteligência o homem se constitui como abertura ilimitada ao horizonte da verdade. Enquanto vontade, ele se abre e se inclina ao horizonte do bem.

\footnotetext{
42 A posição assumida por Lima Vaz diante do niilismo foi desenvolvida por mim em OLIVEIRA, C.M.R. Metafísica e Ética: a filosofia da pessoa em Lima Vaz como resposta ao niislimo contemporâneo. São Paulo, Loyola, 2013.
} 
Ora, ao partir da experiência que faz de si mesmo, o sujeito assume o seu próprio ser como objeto de reflexão, mas ao mesmo tempo não perde de vista o fato de ser ele mesmo o sujeito que interroga e coloca a pergunta pelo próprio ser. Ao colocar esta pergunta ele se descobre como um ser de estrutura, ou seja, como um ser que possui uma constituição ontológica própria. Ele é corpo, psiquismo e espírito. Contudo, tudo isto não basta para conferir sentido àquilo que o homem é. As categorias de estrutura são necessárias, mas insuficientes.

Para Lima Vaz, o homem é também constitutivamente um ser de relações. Ele confere sentido ao seu próprio existir no tempo apenas à medida que estabelece relação de objetividade com o mundo, relação intersubjetiva com outros sujeitos e relação de transcendência com o Outro absoluto. Através do trabalho o homem confere sentido ao mundo no qual vive e desenvolve o seu existir. Ao estabelecer relações de reconhecimento e consenso com os outros, ele constitui a sua humanidade e confere sentido propriamente humano aos seus atos e, portanto, ao seu existir na história. E é, justamente, a relação de transcendência que se apresenta como condição de possibilidade e fundamento último de todo o sentido de nosso existir no tempo da história.

Segundo assim, a superação do niilismo exige que a relação com o mundo seja repensada. A devastação da natureza, o superaquecimento global, por exemplo, revelam a urgência de afirmar o ser do homem como ser-no-mundo e com-o-mundo. A relação de pura dominação, orientada por um modelo operacional de racionalidade, deve ser substituída por uma relação de respeito. Através do trabalho, o homem deveria poder conferir um sentido autêntico para o mundo e ao mesmo tempo afirmar a sua própria dignidade. Mas, para que isso aconteça, a primazia conferida pela cultura à racionalidade poietico ou técnica deveria ser repensada. A racionalidade instrumental precisaria novamente ser submetida aos critérios do saber ético.

As relações entre sujeitos também não podem ser orientadas pelo modelo da racionalidade instrumental. Os seres humanos não podem ser tratados como meros meios para se atingir fins específicos. As relações humanas não devem ser reguladas por critérios de utilidade. Afirmado como fim em si mesmo, o homem deve ser respeitado em sua dignidade. A relação intersubjetiva deve ser orientada, portanto, por um modelo específico de racionalidade que garanta o reconhecimento e o consenso entre os sujeitos.

Lima Vaz propõe, neste sentido, retomar a divisão aristotélica clássica entre os saberes e reafirmar a razão prática como razão própria da práxis. Em conseqüência, ele defende um 
lugar específico para a ética ao lado dos demais saberes. A ética é afirmada, por ele, como ciência da práxis. Esta, por sua vez, entendida em seu sentido mais próprio como energeia.

Mas, para Lima Vaz, as relações do homem com o mundo e do homem com os outros só adquirem sentido próprio e profundo porque estão fundamentas na relação de transcendência. $\mathrm{O}$ absoluto transcendente é condição última de possibilidade de nosso ser no mundo e na história. Em conseqüência, para superar o niilismo e encontrar novamente um sentido humano para o existir e o agir do homem no tempo, faz-se necessário reafirmar o absoluto transcendente.

Ora, o caminho apontado por Lima Vaz, como alternativa ao niilismo, ainda não se realizou na história. A racionalidade unívoca contínua a exercer seu domínio. A primazia do modelo de racionalidade operacional parece se tornar cada vez mais forte. Talvez, para fazer novamente menção à Hegel, devamos ainda olhar de frente para o negativo. Afinal, como o próprio Lima Vaz defendia, quem dará a última palavra não será o filosofo, mas a história.

Isso, no entanto, não significa que devamos adotar uma postura negativa ou conformista diante do niilismo. Como Lima Vaz, vários outros pensadores tentaram indicar caminhos de superação do niilismo. Qual caminho se realizará efetivamente? O niilismo poderá ser superado pela cultura? Só a história dirá. 